International Journal of Engineering \& Technology, $7(3.34)(2018)$ 133-135
International Journal of Engineering \& Technology
SPC
Website: www.sciencepubco.com/index.php/IJET
Research paper

\title{
Providing a Live Chat on Online Shopping with End-to-End Encryption
}

\author{
Mr.S.K.Manigandan ${ }^{1}$,Mrs.R.Latha ${ }^{2}$, Mr.S.MohamedAsik ${ }^{3}$, J.Velmurugan $^{4}$, ,D.Ramya $^{5}$ \\ Assistant professor ${ }^{1,2,4,5}, P G$ Scholar ${ }^{3}$,Department of Master Of Computer Application ${ }^{1,2,3}$, \\ Department of Information Technology $y^{4,5}$ \\ ${ }^{1,2,3,4}$ Vel Tech High Tech Dr. Rangarajan Dr. Sakunthala Engineering College \\ ${ }^{5}$ Vel Tech Rangarajan Dr.Sagunthala R\&D Institute of Science and Technology \\ *Corresponding author E-mail: kgmanigandan@gmail.com
}

\begin{abstract}
In our these days life on-line purchase associated e-commerce website has changing into an mandatory things in our daily life vogue since, it conjointly have some major issue like purchasing a product with unhappy mode and lack of data in product usage. therefore as to overcome these drawback we have a tendency to have new entranceway referred to as live chat in online looking. We have a tendency to will offer this live chat in most safest method exploitation the end to finish cryptography methodology, most of the looking can have a live chat however they Weren't provided a cut price options and most ecommerce website don't have Chat choices. We have a tendency to will even enable the client and producer to Share their thoughts.
\end{abstract}

Keywords: Bargain, Decryption, Encryption, Live chat, Products.

\section{Introduction}

Presently day after day we are going to see big of emerge in e-commerce sites, since the e-commerce sites starts, along with them the drawback has been started at the facet of them, main disadvantage is satisfaction of the customer or user therefore on overcome those problems many answer has been taken and put together with that solutions they had happy many users, as by days passed, the wants of consumer has been improved, of late the disadvantage has been come to the construct live chat, this has meant for creating live chat in on-line wanting and put together on with end to finish cryptography, that make the customer to relax relating to their queries of safety, through this methodology we are going to put together secure the message of consumer like associate confidential chat. No various consumer or user can't access their chats and act with these ideas we've got a bent to put together brought the access for the bargain by the tactic of cryptography.

\section{System Architecture}

This system style has been created absolutely supported the construct of project, this framework will tell you overall work of the net website or project, it describes the full income and outcome of project and the whole methodology of the projects beside, buying product, adding products to cart, payments, delivery of products and put together the chat happen between the client and businessperson[1]. Register login, display roduct, uploading product, Payment gateway payment success error user vendor UN success add to cart amount owing to businessperson requesting for chat [2].

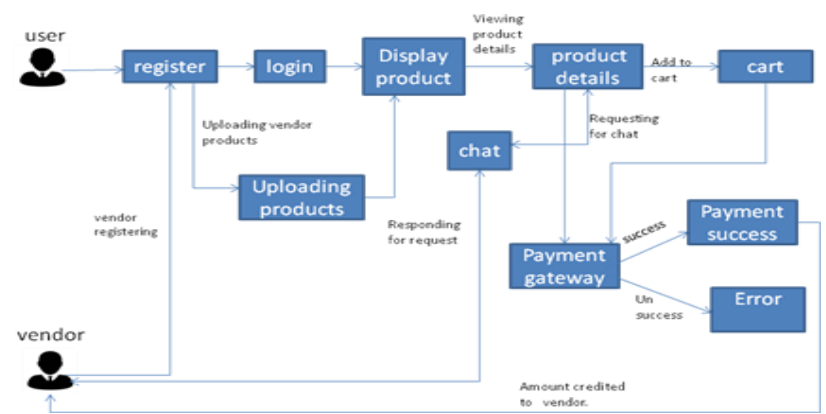

Fig. 1: Architecture diagram

\section{Materials and Methods}

\subsection{Logging In}

Logging in may be an necessary issue in Achproject that has been created in day-to -day life vogue, no project is while not associate in nursing logging in choice, it act as associate in nursing security purpose in project, which is accustomed authenticate the person.

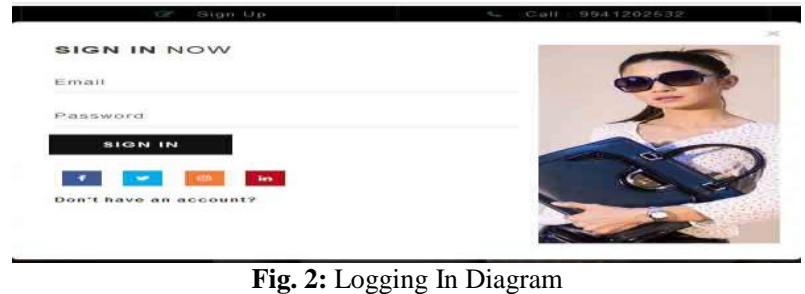

Fig. 2: Logging In Diagram 


\subsection{Product View}

This module that helps for the user to view product and see the list of product details and conjointly they will see the description of the product through its read, let the shoppers decides whether or not they have to purchase the Product or not.



\subsection{Cart}

The cart is changing into Associate in nursing necessary issue in each e-commerce website, as a result of this module can Store product detail that the user can't buy immediately output of the website and conjointly embody the confidential secrets of the client and vendor[3]. If he/she is like to get that product later on they can merely add the merchandise to cart once ever they wish purchase those product they will purchase it from cart ,cart will help to avoid missing the likable product.

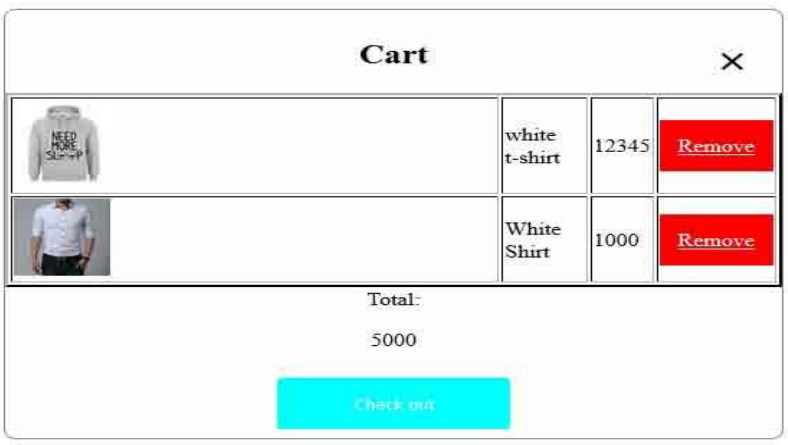

Fig. 4: Cart Diagram

\subsection{Home}

The home module is have the general activities of the websites and manage the whole input and answer, it will not going to be confidential secrets of the client and vendor.

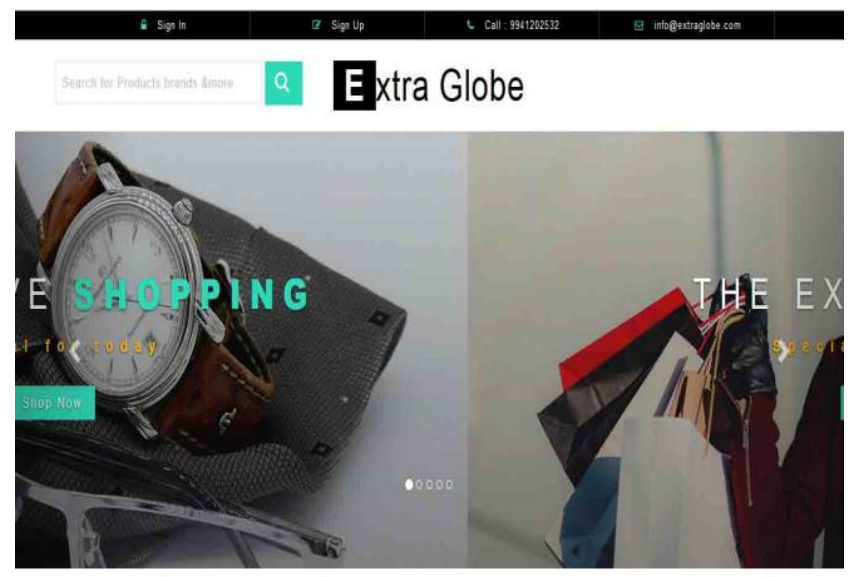

Fig. 5: Home Page Diagram

\section{Existing System}

The most disadvantage of Associate in Nursing existing ecommerce website is, the client gets associate in nursing unsatisfied feeling from their purchase of product through on-line what is mean by unsatisfied? It means that the user world health organization uses online looking purchase they're obtaining the complete data of product with those reviews and details viewed in postal though several e-commerce apps and internet sites have a chat however that is not directly to purchase the chat can finish up within the admin and conjointly can have solely chat like question and answer.

\subsection{Proposed System}

In this proposed system the technique which has been used that can be reaching to be helpful for each purchaser and seller in online looking web site, the useful is nothing however that the user and seller is going to chat freely while not any interaction through the safety way[4],[5]. this system can overcome the barriers between the purchaser and vendor so, here we have a tendency to had been used away called live chat through encrypted method

\subsection{Algorithm}

During this project we have a tendency to square measure reaching to use the RSA algorithmic program for the safety purpose ,this algorithmic program can receive a knowledge from sender and write in code and send the information and the receiver can receive the information and decipher the information[6],[7].Step1:generate the 2massive prime $\mathrm{p}$ and letter of the alphabet of about equal size such that their product $n=p q$ is of needed bitStep 2: reason $n=p q$ and $(p h i) \varphi=(p-1)(q-1)$. Step 3 : opt for Associate in Nursing whole number e, one < e <letter of the alphabet, such that $\operatorname{gcd}(\mathrm{e}, \mathrm{phi})=1$ Step 4 : reason the key exponent $\mathrm{d}, 1<\mathrm{d}<$ phi, specified by function $\equiv$ one (mod phi).Step 5: the general public secret's (n, e) and therefore then on-public key (d, p, q). Keep all the values d, p, q and phi secret.

\section{Result}

One person will feel comfort by purchasing in on-line not solelybuying but conjointly doing live chat with retailers, these Technical improvement create the user to feel comfort and conjointly safety too [8], [9]. With these further options the shopping become easier and the user can ready to grasping detail concerning the product he/she is going to purchase

\section{Future Enhancement}

In this paper we have a tendency to see how ever e-commerce website got improved, however this improvement in this technology is not going to stop with itself, if we have a tendency towish to add further features in future it could conjointly done and the facilities is reaching to beads cititious in this project issolely primarily based on the requirement of the customers. In a growing technical world the on-line shopping plays associate in Nursing very important role, thus in this e-commerce sites the \{additional $\}$ or additional features will beads cititious simply.

\section{Conclusion}

In this paper we have a tendency to have that however live chat works in e-commerce website and the way consumers got benefited by those services [10], but these variety of enhancements cannot going to stop this could are some drawbacks, even this disadvantage can be rectified in future. The further options in this paper will be adscititious according to the demand of client. 


\section{Acknowledgement}

The authors thank the Principal and Management of Vel Tech High Tech Dr. Rangarajan Dr. Sakunthala Engineering College for providing necessary lab facilities to conduct the experiments required to complete the study

\section{References}

[1] G. Draper-Gil, A. H. Lashkari, M. S. I. Mamun, A. A. Ghorbani, "Characterization of encrypted and VPN traffic using time-related features", Proceedings of the 2nd International Conference on Information Systems Security and Privacy(lCISSP), pp. 407-414, 2016.

[2] Yemei, Talking about online shopping logistics service evaluation ,E-Business Journal,2011,vol.1,no.1,pp.20-25.

[3] L. Ting, Z. Hongmei, "The Empirical Analysis of Effecting Online Banking Information Security Products Customer Satisfaction", 7th International Conference on Intelligent Human-Machine Systems and Cybernetics (IHMSC), vol. 1, pp. 398-402, 2015.

[4] Z. Ma, "Assessing Serviceability and Reliability to Affect Customer Satisfaction of Internet Banking", Journal of Software, vol. 7, pp. 1601-1608, July 2012.

[5] Zuva Tranos, O. Olugbara Oludayo, O. Ojo Sunday, M. Ngwira Seleman, "Image Content in Location-Based Shopping Recommended Systems for mobile users", Advanced Computing: An International Journal (ACIJ), vol. 3, no. 4, July 2012.

[6] S M Pavalam, S V Kashmir Raja, K Akorli Felix, M Jawahar, "A Survey of Web Crawler Algorithms", IJCSI International Journal of Computer Science Issues, vol. 8, no. 6, November 2011.

[7] B. O. B. Kamwendo, "Vulnerabilities of signaling system number 7 (ss7) to cyber attacks and how to mitigate against these vulnerabilities. bob kamwendo," vol. 7, no. 7, 2015.

[8] A. Kirlik, Adaptive perspectives on human-technology interaction: Methods and models for cognitive engineering and humancomputer interaction. Oxford University Press, Inc., 2009.

[9] P. Velan, M. Cermak, P. Celeda, M. Drasar, "A survey of methods for encrypted traffic classification and analysis", International Journal of Network Management, vol. 25, no. 5, pp. 355-374, 2015

[10] 10. Z. Cao, G. Xiong, Y. Zhao, Z. Li, L. Guo, "A survey on encrypted traffic classification" in Applications and Techniques in Information Security, Springer, pp. 73-81, 2014 